Article

\title{
Wind Power Development and Energy Storage under China's Electricity Market Reform-A Case Study of Fujian Province
}

\author{
Dunguo Mou ${ }^{10}$ \\ School of Economics, Xiamen University, Xiamen 361005, China; billmmu@xmu.edu.cn
}

Received: 20 December 2017; Accepted: 20 January 2018; Published: 24 January 2018

\begin{abstract}
This paper, based on the Fujian provincial $500 \mathrm{kV}$ grid and part of the $220 \mathrm{kV}$ grid and the key power plants, including hydro, coal, nuclear, gas, wind and pumping and storage hydro powers (PSHP) connected to the grid, constructs an independent electricity market model. Using data that are very close to reality about coal fired power production costs, along with data about power plants' technical constraints, this paper studies the effect of wind power on Fujian's provincial electricity market. Firstly, the paper analyzes the relationship between wind speed and wind power output and the effects of short-term power output fluctuation on frequency modulation and voltage regulation. Secondly, under supposition of the production costs following quadratic functions, the paper analyzes the effects of changes in wind power output on the electricity supply costs under optimal power flow. Thirdly, using the bidding model in the Australian Electricity Market Operator for reference and supposing that, in a competitive market, coal fired power plants can bid 6 price bands according to their capacity, the paper analyzes effects of wind power on electricity prices under optimal power flow, the stabilizing effects of PSHP and the minimum PSHP capacity needed to stabilize the electricity market. Finally, using a daily load curve, this paper simulates the electricity prices' fluctuation under optimal power flow and PSHP's stabilizing effect. The results show that, although PSHP has a large external social welfare effect, it can hardly make a profit. In the end, this paper puts forward some policy suggestions for Fujian province's wind and nuclear power development, PSHP construction and electricity market development.
\end{abstract}

Keywords: wind power; electricity market reform; energy storage; PSHP

JEL Classification: D41; Q21; Q41

\section{Introduction}

In the past 30 years, China's electricity market has been in a dynamic process of adjustment. From 1985, the main mission of the power system has been to solve the electricity shortage problem caused by rapid economic growth. The State Council of China signed the No. 5 document [1], on 10 February 2002, establishing a series of objects for further electricity market reform. However, in the following ten years, there was no substantive progress in these reform objectives. After 2012, the Chinese economy entered the so called "New Normal" mode and the economic growth rate slowed; the electricity industry became oversupplied; the price of coal fell, making coal power profitable; and renewable energy expanded rapidly. All of this created a good environment for deepening electricity industry reform. The Communist Party of China (CPC) Central Committee and the State Council released the No. 9 document [2]. Shortly after this, the National Development and Reform Commission (NDRC) and National Energy Administration released a series of supporting documents.

In the process of electricity marketization, Fujian is not radical but is cautious and it is steadily pushing electricity marketization forward. In July 2017, the total power installed capacity in Fujian 
province is near $50 \mathrm{GW}$, including 9172.5 MW from hydro power, 29,524.6 MW from thermal power, 8640 MW from nuclear power from Ningde and Fuqing plants and 2305.9 MW from wind power. In July, the highest provincial peak load is $34,230 \mathrm{MW}$ and the electricity market is oversupplied. According to the policies, renewables and nuclear powers belong to the first class of priority generation; for example, in 2016, the generation hours of the key coal fired power plants in Fujian ranged from 2000 to 3000, meanwhile the generation hours of the two nuclear power plants were close to 7000 . In the 13th Five Year Plan, Fujian Province plans to install 5000 MW wind power at the end of 2020; 3000 MW of this will be onshore and 2000 MW will be offshore. The National Energy Administration has approved the 17 offshore wind farm plan, with 13,300 MW installed wind power capacity. To assist the development of renewable and nuclear power plants, Fujian has decided to construct pumping and storage hydro power (PSHP) plants. Currently, there is only one PSHP plant $(4 \times 300 \mathrm{MW})$ in Xianyou but the government has decided to launch the construction of the Xiamen $(4 \times 350 \mathrm{MW})$, Yongtai $(4 \times 300 \mathrm{MW})$ and Zhouning $(4 \times 300 \mathrm{MW})$ PSHP plants during the 13th five-year-plan period. When the total installed wind power increases, electricity marketization in Fujian Province will be challenged.

The increased capacity of intermittent renewable energy sources increases the need for flexibility in energy system and the effects of large scale penetrations of wind power in electricity systems have been extensively studied ([3-5]); Huber et al. [6] show that increasing wind and solar power generation above a $30 \%$ share in annual electricity consumption will significantly increase flexibility requirements. The crossroads of capital-intensive, base-load nuclear power and intermittent renewable energy may entail new challenges in the optimal and economic operation of power systems [7]. The results of Zakeri et al. suggest that nuclear power constrains the room for maximum uptake of wind energy by a descending parabolic relationship; heat storage and flexible demand demonstrate efficient ways in reducing the power oversupply in Finnish power system. Were without flexible generation units, system operators usually implement system operational constraints (SOCs) in order to maintain stability with high wind generation but resulting in wind curtailment.

Introducing large-scale storage schemes entails a number of additional system-wide benefits, such as reduction of required investment in generation, transmission and distribution assets [8]. In a large number of existing studies addressing energy storage alternatives for future electric power systems, PSHP is found to be the most mature, efficient and cost-effective technology ([9-11]). Suul et al. [12] found that, for an independent power system with a renewable electricity source, PSPH is very important and can provide a frequency control function either when the demand for electricity is low or when the highly fluctuating renewable electricity is in operation. PSHP has experienced rapid growth in recent years. Deane et al. [13] reviewed PSHP development in Europe, Japan and the USA from a techno-economic aspect, finding that the drivers of new PSHP capacity growth include large scale expansion of unstable renewable energy; growing demand for peak load; increasing interconnections and coordination between regional markets, providing more profitable opportunities; requirement for a more secure supply; and demand for improved efficiency of existing facilities.

In the vertically integrated electricity market, coordination between PSHP and thermal power can be exploited to reduce fuel costs and decrease emissions; thus, optimal arrangement of PSHP use becomes a key question. The marginal cost approach was first applied to evaluating and arranging coordination between PSHP and other kinds of electricity generation [14]. In consideration of the PSHP characteristics, Cohen and Wan [15] designed an algorithm for arranging large-scale PSHP use. Oliviera et al. [16] applied a mixed-integer linear program method to study the cost efficiency of PSHP under an economic system framework.

In a competitive electricity market, there is still the technical need for energy storage but profitability becomes the challenge to its development $([11,17])$. How to increase profit by properly bidding in the given market with changing prices has become a hot topic and there are many studies on PSHP bidding strategies in competitive markets. Horsley et al. [18] applied linear and convex programming methods to rental valuation of facilities for conversion and storage goods, such as energy, by shadow pricing the stock. In competitive markets with time-varying prices, PSHP pumps 
water when the price is low and generates power when the price is high. It can arbitrage by buying in the bilateral market and selling in the spot market. However, exploiting the market to make a profit is very technically demanding. By supposing that the market clearing price is not sensitive to unique generators' bids, Lu et al. [19] put forward an optimal bidding strategy for PSHP in competitive markets. In the real competitive market, PSHP's optimal bidding may face many constraints [20]. Based on a forecast hourly market clearing price, Kanakasabapathy and Swarup developed optimal bidding strategies for a PSHP in a pool-based electricity market using a multistage looping algorithm to maximize the profit of a pumped-storage plant. Dogan [21] estimated the influence of an intraday continuous market on PSHP and Abgottspon et al. [22] took the long-term and the hourly day-ahead market into one optimization function to discuss the influence of a price maker. Braun [23] analyzed the short-term hydro power optimal strategy in the spot and intraday auction market and found that there is a significant difference between the two markets, because of higher fluctuation and limited liquidity in the intraday auction market.

Analysis of price arbitrage alone underestimates the function of PSHP in the electricity markets and constrains the potential earnings. Kumar et al. [24] performed a systematic review of the cycling cost and load following constraints amongst several traditional coal-fired power and gas power technologies. Compared with these thermal powers, hydro power, with a low cost of restart and a high ability of load following, can play a greater role in the electricity ancillary service market. Deb [25] discussed the need for PSHP to participate in the energy and ancillary services markets. Ela et al. [26] pointed out that the recent changes in the electricity market and the growing variable renewable energy generation allows PSHP to earn more profit by providing other ancillary services, and, as the market design continues to evolve, there are still ways in which designs can improve the values of services offered by PSHP while maintaining a fair and impartial perspective of the market. Recent technological advances enable PSHP to take potential advantage of the ancillary services' market. While traditional PSHP facilities cannot provide ancillary services, either while pumping or when idle, the new adjustable speed PSHP has the ability to provide services while pumping and the flexibility enhanced PSHP can profit from expected fluctuations in both energy and ancillary service prices [27]. In the European market, the integration of large scale intermittent renewable energy sources has resulted in demands to improve system flexibility; PSHP is the only system capable of large-scale commercial operation.

When evaluating the flexibility requirements of power system with high penetration of renewable source energies, net load is considered by some studies $[5,6,28]$. Net load is defined as the conventional load minus the non-dispatchable generations; it is an intuitive basis of operation planning in day-to-day delivery of electricity to the consumers. But most studies evaluate the flexibility requirement from whole power system aspect. This paper, based on real cost data, analyzes the effect of wind power on the Fujian electricity system, and, using the market operation and price bidding modes in the developed electricity market as reference, analyzes the effect of wind power on market price fluctuation, the buffering effects of PSHP and the potential profit of PSHP.

The remainder of this this paper is structured in four Sections. Section 2 demonstrates the electricity market equilibrium model that maximizes social welfare and the grid system, generation cost data; Section 3 analyzes the wind power impacts on grid system from three aspects; Section 4 simulates the price fluctuation along with the demand load changes and analyzes the PSHP's profit potential; Section 5 concludes this paper with some policy suggestions.

\section{Model and Data}

\subsection{Model}

To study the effects of intermittent wind power and PSHP on the operation of the electricity market, this paper is based on two systems: (1) the factual physical regional AC grid system, which is the platform that fulfils the function of transmitting electrical energy from power plants to consumers; 
(2) the market bidding system based on the physical system, in which power plants and consumers provide their bids and prices and the system sorts these bids and constructs the market demand and supply curves for each trading period to find the balance of the electricity market and arrange electricity generation for power plants.

In the current electricity market, power plants' feed in prices are determined by the NDRC according to the generators' historical construction costs, loan repayments, fuel costs and certain level of profit. An egalitarian approach is taken when arranging generation hours, with each power plant having a certain share. Low-efficiency generators may have the same hours as high-efficiency generators [29] to ensure that all generators' profits are at almost the same level. The Grid Company is a double-headed monopoly and is in charge of grid system stabilization. However, the situation is changing slowly to a competitive market model. In a competitive market, generators and consumers bid to their prices and volumes to the market according to either their marginal costs or their marginal utility; these biddings are sorted by price, forming the demand and supply curves and the deal price is the market clearing price, which maximizes social welfare in an economic sense. In the real competitive market, which is constrained by many factors, the bidding price of suppliers may not equal the marginal cost. In the Pool market mode, as the marginal biddings determine the market price, there are many "free riders" with "zero" price biddings at valley load periods just to ensure their minimum generation powers; while, at the peak load period, there may be very high price bids from generators with surplus capacities, squeezing the market to make more profit. Nevertheless, marginal biddings are still the best indices for reflecting the demand-supply situation in the market. On the other side, electricity supply and demand are spatially distributed and market equilibrium is constrained by the transmission capacity. The object of a spatially distributed competitive electricity market is to maximize the welfare function under a series of constraints. In mathematical form, it can be written as

$$
\begin{gathered}
\operatorname{Max}\left(\sum C_{D i} P_{D i}-\sum C_{S k} P_{S k}\right) \\
\text { s.t } g\left(\delta, V, Q_{G}, P_{S}, P_{D}\right)=0 \\
0 \leq P_{S} \leq P_{S_{\max }} \\
0 \leq P_{D} \leq P_{D_{\max }} \\
\left|P_{i j}(\delta, V)\right| \leq P_{i j \max } \\
\left|P_{j i}(\delta, V)\right| \leq P_{j i \max } \\
Q_{G_{\min }} \leq Q_{G} \leq Q_{G_{\max }} \\
V_{\min } \leq V \leq V_{\max }
\end{gathered}
$$

where $g(\cdot)$ is the power flow function, $C_{S}$ and $C_{D}$ are bidding price vectors of supply and demand, respectively, with units of RMB/MWh; $P_{S}$ and $P_{D}$ are supply and demand bidding volume vectors; $V$ and $\delta$ are AC voltage and phase angel; $Q_{G}$ is the reactive power; $P_{S_{\max }}$ and $P_{D_{\max }}$ are maximum powers of supply and demand; $P_{i j}(\delta, V)$ is the power flow between two nodes studied; $P_{i j \max }$ is the maximum power flow; and $V_{\min }, V_{\max }$ are voltage constraints. For the multi-price bidding model, suppose buyers and sellers in the electricity market can offer several bidding prices, the welfare function can be written as:

$$
\operatorname{Max}\left(\sum_{i} \sum_{m} C_{\text {Dim }} P_{\text {Dim }}-\sum_{k} \sum_{m} C_{S k l} P_{S k l}\right)
$$

This model is a typical optimal power flow (OPF) problem in the electricity system, which can be solved by many power flow system software. For this paper, it is solved by the software PSAT2.1.10 (See Federico Milano's Webpage, http:/ / faraday1.ucd.ie/psat.html.), in which there are several algorithms for choice and the Newton-Raphson algorithm is used for calculation. 
For a generator $i$, suppose that the average variable cost is a linear function of power generation, written as

$$
A V C_{i}=C_{P_{1 i}}+\beta_{i} \cdot P_{S i}
$$

As the power increases, total variable cost is a quadratic function of power generation. Taking fixed cost (calibrate in $\mathrm{RMB} / \mathrm{h}$ ), the total cost is a quadratic function of power generation with 3 items, written as

$$
\begin{gathered}
C_{S i} P_{S i}=C_{P_{0 i}}+C_{P_{1 i}} P_{S i}+C_{P_{2 i}} P_{S i}^{2} \\
C_{Q_{i}} \mathrm{Q}_{S i}=C_{Q_{0 i}}+C_{Q_{1 i}} \mathrm{Q}_{S i}+C_{Q_{2 i}} \mathrm{Q}_{S i}^{2}
\end{gathered}
$$

where $C_{S i}$ and $C_{Q i}$ are active and reactive power costs, respectively, of generator $i ; C_{P_{o i}}$ and $C_{Q_{0 i}}$ are fixed cost of active and reactive powers, with a unit of RMB $/ \mathrm{h} ; C_{P_{1 i}}$ and $C_{Q_{1 i}}$ are generator specific average variable costs, with a unit of RMB/MWh; and $C_{P_{2 i}}$ and $C_{Q_{2 i}}$ are a quadratic coefficient, describing the economy of scale, with a unit of $\mathrm{RMB} / \mathrm{MWh} 2$. Reactive power is very important to the electricity system but it is not considered in this paper. For static analysis of electricity market, usually there is a demand curve with a negative slope to price

$$
P_{D i}=n_{0}+\beta_{D i} * P P
$$

With $P P$ being the electricity prices and $\beta_{D i}<0$. However, electricity demand has characteristics of price rigidity and load ramping and the time series of demand can be written as

$$
P_{D i t}=n_{0 t}+\beta_{D i} * P P_{t}
$$

where $n_{o t}$ is the time varying basic demand; this may ramp quickly and its effect on final loads is much higher than is the depressing effect of $\beta_{D i}$, resulting in demand load change in the same direction as price. For this reason, this paper ignores the item of $\beta_{D i}$, supposing that the consumers accept any price determined by the supply curve. Thus, the demand total cost of electricity consumption can be written as

$$
C_{D i} P_{D i}=C_{D_{o i}}+C_{D_{1 i}} P_{D i}
$$

Thus, the market is formed by the up-slope supply curve and the vertical demand curve, as shown in Figure 1. From the static aspect, equilibrium is the intersection of the supply curve (S) and the demand curve (D); the equilibrium power is $P_{D}$ and equilibrium price $C$; from dynamic aspects, $\mathrm{D}$ may ramp to either left or right and $S$ can ramp to either up or down, making the equilibrium vary over a wide range. This paper supposes that the supply curve stays put.

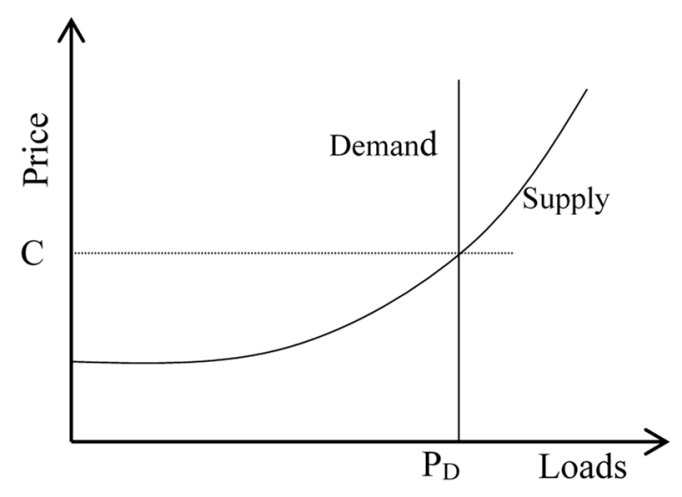

Figure 1. Electricity market equilibrium with inelastic demand curve. 


\subsubsection{Power Plants}

Power plants are the key elements of the supply side in the electricity market. Fujian has a complete power supply system, with renewables that include many small hydro power, wind power and PV power plants, along with traditional power plants that include hydro plants, PSHP, coal-fired plants, gas peaking plants and nuclear plants. Of these power plants, the key power plants (not including the 3 gas peaking power plants) identified by Fujian Electric Power Supply Association (FEPSA) and their installed capacities are listed in Table 1. Besides the wind farms in Table 1, at prefectural level, other coastline cities, including Quanzhou (44 MW), Putian (592 MW), Fuzhou (528 MW) and Ningde (42 MW), also have wind power.

Table 1. Key power plants and installed capacities (Cap.) in Fujian Province.

\begin{tabular}{|c|c|c|c|c|c|}
\hline Plant & Cap. (MW) & Plant & Cap. (MW) & Plant & Cap. (MW) \\
\hline Fuzhou & 1400 & Hongshan & 1200 & Xiamen Gas & 780 \\
\hline Songyu & 1200 & Ningde Nuke & 4320 & Zhao'an County & 48 \\
\hline Nanpu & 1940 & Fuqing Nuke & 4320 & Dongshan County & 85.5 \\
\hline Ningde & 2520 & Shuikou Hydro & 1400 & Yunxiao County & 19.5 \\
\hline Jiangyin & 1200 & Mianhuatan Hydro & 600 & Longhai County & 224 \\
\hline Longyan & 1140 & Qianyun Gas & 1560 & & \\
\hline
\end{tabular}

\subsubsection{The Grid System}

The grid system is the physical platform on which the electricity market operates. The Fujian grid belongs to the Eastern China Grid, which is connected to the Zhejiang grid by 2 circuits of $1000 \mathrm{kV}$ $\mathrm{UHV}$ and 2 circuits of $500 \mathrm{kV}$ lines. Within the Fujian grid, the $500 \mathrm{kV}$ high voltage lines form a ring network and a north-south double-loop backbone network. The $500 \mathrm{kV}$ transmission system and the power plants connected to it are shown in Figure A1 in the appendix. Other power plants are mainly connected to the $220 \mathrm{kV}$ grid; most of the wind power plants are connected to the local $110 \mathrm{kV}$ grid and the small hydro power plants are connected to the local $35 \mathrm{kV}$ grid. To study the electricity market operation at the provincial level, research was carried out at the $500 \mathrm{kV}$ and $220 \mathrm{kV}$ levels, except for the power plants in Figure A1 in the appendix. Other power plants are taken as being connected to the regional $220 \mathrm{kV}$ grid and the Simulink illustration is shown in Figure A2 in the appendix. The power supply area of the Nanpu power plant is not clear; it is taken to be connected to the $500 \mathrm{kV}$ grid. Gas peaking power, small hydro power and wind power plants are ignored, either because there is no public available information about their connections or because they are renewable but unstable sources that may pose a greater challenge to the electricity system.

As wind power is connected to a lower voltage grid, its change will first effect the $220 \mathrm{kV}$ grid; when the regional grid cannot handle this change, it will affect the provincial $500 \mathrm{kV}$ grid. This paper takes Zhangzhou City's installed wind power and the $220 \mathrm{kV}$ grid system as an example to study the effect of wind power on the provincial electricity system. Zhangzhou City's $220 \mathrm{kV}$ grid is connected to the provincial $500 \mathrm{kV}$ backbone grid by the Zhangzhou and Wufeng transformer substations and it is also connected to Xiamen and Longyan cities' $220 \mathrm{kV}$ grid for small-scale electricity adjustment. The lower left corner part of Figure A2 illustrates Zhangzhou City's $220 \mathrm{kV}$ grid connections. When the planned Zhangzhou nuclear power plants and the large scale off-shore wind power operation are put into operation, Zhangzhou City's $220 \mathrm{kV}$ grid will change greatly and the provincial $500 \mathrm{kV}$ backbone grid will change to a certain degree. As the Fujian 13th Five-year plan depicted, the $1000 \mathrm{kV}$ grid will extend to Xiamen City, which will change the provincial backbone grid greatly. 


\subsubsection{The Power Generation Costs}

In the electricity market, whether a generator can provide electricity to market is determined by its cost or its bidden prices under the OPF, which solves the market equilibrium. Data from NDRC's feed in benchmark prices, industrial reports and media reports show that, in general, the cost of coal fired power is approximately RMB 300-400/MWh, the cost of hydro power is approximately RMB 200-300/MWh, the cost of nuclear power is approximately RMB 300-400/MWh and the cost of wind power is approximately RMB 600/MWh. The costs are different according to regions and projects.

The power plants' production costs, as revealed in Equation (3), are confidential material. However, the State-owned Assets Supervision and Administration Commission of the State Council published the "Investigation Report on an Audit of Some Thermal Power Enterprises' Power Generation Costs," which pointed out that the fixed costs include depreciation, labor costs and maintenance fees and estimated the average costs of generators with capacities lower than $300 \mathrm{MW}, 300-600 \mathrm{MW}$ and above $600 \mathrm{MW}$. This paper applies these average fixed costs' data to generators accordingly.

As to the variable costs of the coal-fired power plants, the Statistical Yearbook data are rather general; they give only the averages. Based on plants' internal Supervisory Information System data, Wang (2009) analyzed the relationship between average variable cost (AVC, unit: RMB/MWh) and power generation (MW) of a $300 \mathrm{MW}$ generator. The data show that, at $60 \%$ capacity load level, the coal consumption per unit of electricity is $313.65 \mathrm{KG} / \mathrm{MWh}$, supposing that the standard coal price is RMB 460/Ton and the variable cost is RMB 167.7/MWh (including water and other inputs costs). In the Statistical Yearbook, the average generation hours are approximately 5000 , which equal $60 \%$ of the average load and the coal consumptions per unit of electricity of Fujian coal-fired power plants are listed, allowing these plants' variable costs to be calculated proportionally. As the generation load increases, the average cost lowers; for the $300 \mathrm{MW}$ generator, the regression coefficient of $\beta$ in Equation (2) is approximately -0.08 . This negative coefficient explains the violent competition in Guangdong electricity market when electricity is oversupplied. It also explains why the bilateral direct transaction operates at a loss in Fujian. The negative coefficient shows the economy of scale in thermal power.

In September 2017, the price of $5000 \mathrm{Kcal}$ (The Chinese Coal industry standard, equals 20,920 KJ) thermal coal of Qinghuangdao port is approximately RMB580/ton, which means that the CIF price in Fujian is approximately RMB $640-680 /$ ton and the standard coal price is approximately RMB 900-950/ton. A 600 MW generators' variable cost of RMB 157/MWh calculated by Wang's (2009) standard becomes approximately RMB 300/MWh. Thus, all the calculated variable costs are doubled; this is very close to the real situation. Although there is economy of scale in coal consumption in coal-fired power plants, when other factors are considered, the marginal cost may rise as generation power increases. Without more information, the $\beta$ is assumed to be positive. For the $300 \mathrm{MW}$ generators, when taking the doubled variable cost into consideration, suppose that $C_{P_{2, i, 300}}=0.16$, and, for other generators of capacity $\mathrm{n}$, suppose that $C_{P_{2, i, n}}=300 / n * 0.16$, to ensure the same economy of scale.

Ogayar et al. [30] developed some equations to calculate the costs of small hydro powers but it cannot be used in this paper, because hydro powers will not participate in the competitive market and the government has a historical criterion to determine their feed in price. Hydro and nuclear power plants' fixed costs are calculated according to their average construction cost, with a 20-year repayment term; hydro power variable costs are assumed to be RMB 200/MWh and nuclear power variable costs are assumed to be the same as are those of the Ultra Super Critical coal-fired power plants with a capacity of $1000 \mathrm{MW}$. The quadratic coefficients of hydro and nuclear power are assumed to be zero.

Although the cost of wind power is high, the Chinese government subsidizes it, the subsidy number being the difference between the benchmark feed in prices of coal-fired power and wind power. As to the wind power benchmark feed in price, the government issued a new document [31] to adjust it in 2016; this document classifies the onshore wind farms into four classes of wind resources, with benchmark feed prices for newly built wind power plants being RMB 400, 450, 490 and 570/MWh, 
respectively. Further, the document also determines the off-shore wind power feed in price: the price for an intertidal zone wind power project is RMB 750/MWh and the price for an off-shore wind power project is RMB 850/MWh. Moreover, the newest information shows that the Chinese government plans to cancel wind power subsidies in 2020-2022, after which wind power should compete with other powers at the same level.

During 2014 and 2015, under the electricity oversupply situation, some coal-fired power plants refurbished their facilities and tested their valley load following ability, finding that the generation load can reach $30 \%$ of capacity without oil input. In this paper, the minimum power output is assumed to be $40 \%$ of their capacity; the hydro power's minimum is assumed to be $20 \%$ and the nuclear power's minimum is assumed to be $60 \%$.

For the demand cost in Equation (3), $C_{D_{o}}$ is the capacity price-RMB 18,000/MVA.month-and this price is applied to each demand node's capacity. Nuclear power is classified as a first priority generator that does not participate in market trade. As Guangdong has included it in market competition, it can be expected that Fujian may incorporate it in market competition in the near future; thus, it is assumed to compete with coal-fired power in the market.

\section{The Operation of Fujian's Provincial Electricity System}

To study the effect of wind power on the electricity system and the electricity market, in addition to the buffering effect of PSHP between electricity demand and supply at the provincial level, this paper takes the Fujian electricity market as an independent system and simulates the system operation on the basis of certain suppositions. The study is carried out in three levels: firstly, to study the systematic effect of intermittent wind power on the electricity system, i.e., on the physical conditions of system voltage, current stability and demand-supply balance; secondly, to study the effect of intermittent wind power on the cost of electricity under different cost suppositions; and, finally, to study the effect of energy storage, through the example of PSHP, on electricity market operation.

\subsection{The Wind Resource in Fujian Province and Wind Power Production}

Along the $3752 \mathrm{~km}$ coastline of Fujian province, the wind resource is rather rich. According to the Wind Energy Resource Survey carried out by Fujian Provincial Meteorological Bureau, at $70 \mathrm{~m}$ height along the coastline, the technical developable area with average wind power density $\geq 400 \mathrm{~W} / \mathrm{m}^{2}$ is $1825 \mathrm{~km}^{2}$ and the total exploitable wind power resource is approximately $6560 \mathrm{MW}$. From the spatial aspect, the wind power distribution is as revealed by Figure 2. In general, the wind power along the coastline exhibits good regularity: seasonally, wind power is characterized by the largest speed in fall, followed by winter and then summer; on a daily basis, wind power is characterized by the smallest in early morning, gradually increasing to reach a maximum during the afternoon to the evening and then gradually decreasing.

Of the wind power generators of Fujian province, those installed at an early stage mostly have a capacity of $1.5 \mathrm{MW}$, while those installed recently mostly have a capacity of $2 \mathrm{MW}$, with some having a capacity of $2.5 \mathrm{MW}$. The $2 \mathrm{MW}$ generators have 3 blades, each $45 \mathrm{~m}$ long, a cut in threshold wind speed of $3.5 \mathrm{~m} / \mathrm{s}$, a rated wind speed of $12 \mathrm{~m} / \mathrm{s}$ and a cut-out threshold wind speed of $25 \mathrm{~m} / \mathrm{s}$. In the simulation system of this paper, it is supposed that all the wind power generators are Variable Speed Wind Turbine with Direct Drive Synchronous Generator with a capacity of 2 MW. 


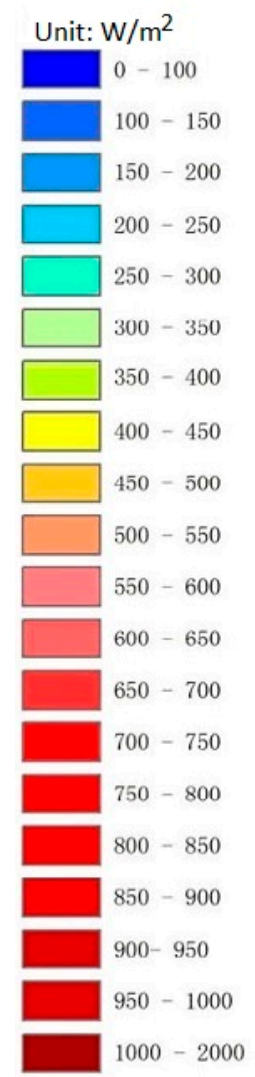

$0 \quad 37.5 \quad 75$

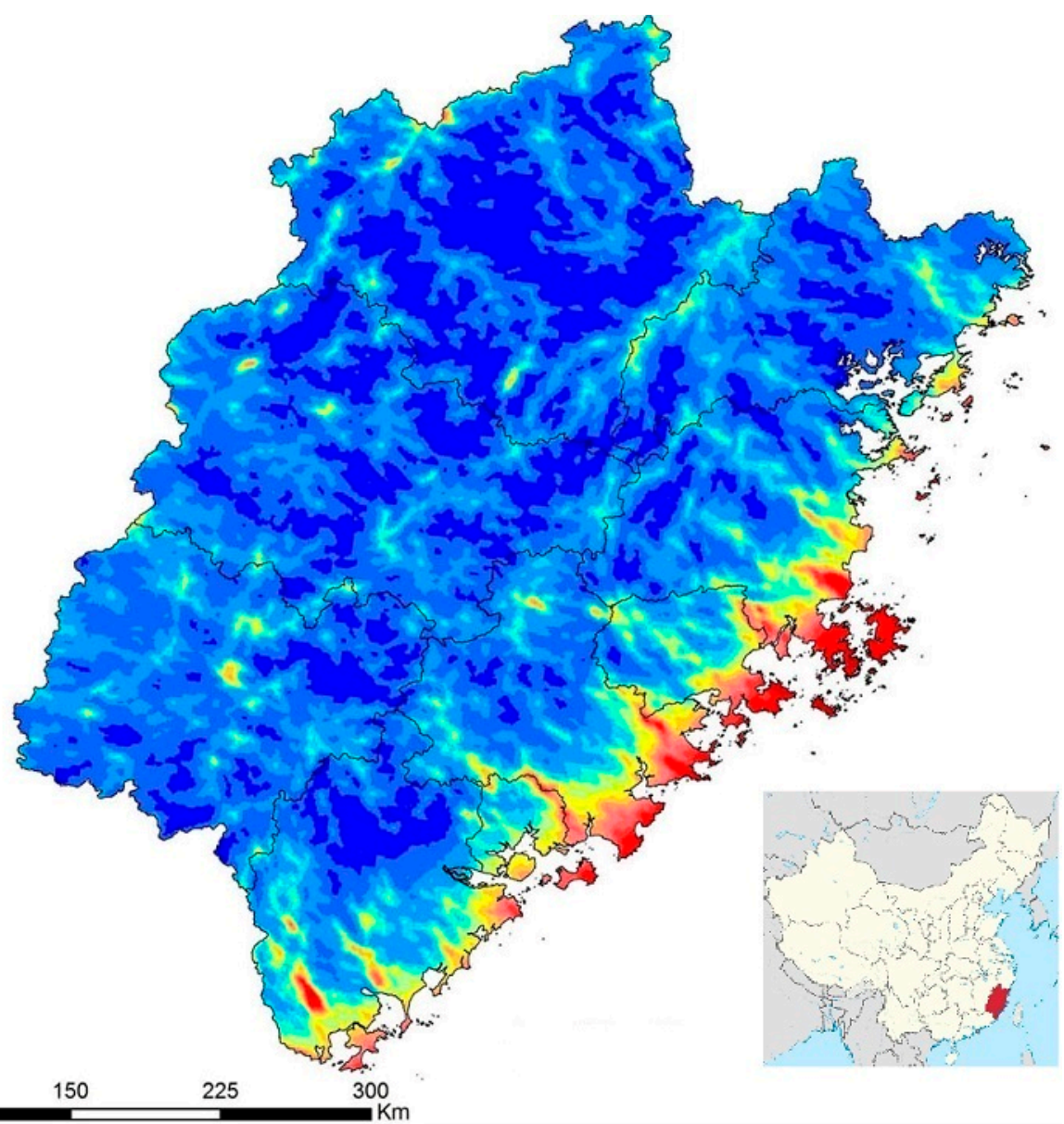

Figure 2. The Fujian provincial wind power density distribution map. Source: Fujian Provincial Meteorological Bureau website. http:/ / www.fjqx.gov.cn/qhzy/201204/t20120410_12343.htm.

To determine the relationship between wind speed and the power of the generators, a study at the Zhao'an wind power farm is carried out, with a total installed capacity of $48 \mathrm{MW}$, under the supposition that the air density is $1.225 \mathrm{~kg} / \mathrm{m}^{3}$ at $15^{\circ} \mathrm{C}$. At time 0 , suppose that the generators are providing electricity at the very small power level of $1.92(48 \times 4 \%) \mathrm{MW}$ and that the wind speed starts from $0 \mathrm{~m} / \mathrm{s}$ and rises at a rate of $1 \mathrm{~m} / \mathrm{s}^{2}$; the actual wind speed values that are used for calculating the mechanical power of wind turbines are the output of a low-pass filter with a time constant of $\tau$ seconds. For $\tau=1$ and $\tau=4$, the relationship between real wind speed and the wind farm's power output is illustrated by Figure 3 .

From Figure 3a, it can be seen that, when the wind speed is above $4 \mathrm{~m} / \mathrm{s}$, the generators begin to supply electricity; when the wind speed is close to $10 \mathrm{~m} / \mathrm{s}$, the electricity output reaches its designed power of $48 \mathrm{MW}$; as the filter time constant $\tau$ rises to $4 \mathrm{~s}$ (see Figure $3 \mathrm{~b}$ ), both the threshold wind speed for supplying electricity and the speed for designed rate rise accordingly; this is caused by the supposition about wind speed. For the filtered wind speed, which causes the generator to spin, the threshold speed of supplying electricity is $3.2 \mathrm{~m} / \mathrm{s}$ and the speed for maximum power output is $9.2 \mathrm{~m} / \mathrm{s}$; these are very close to wind threshold parameters of a real generator. 


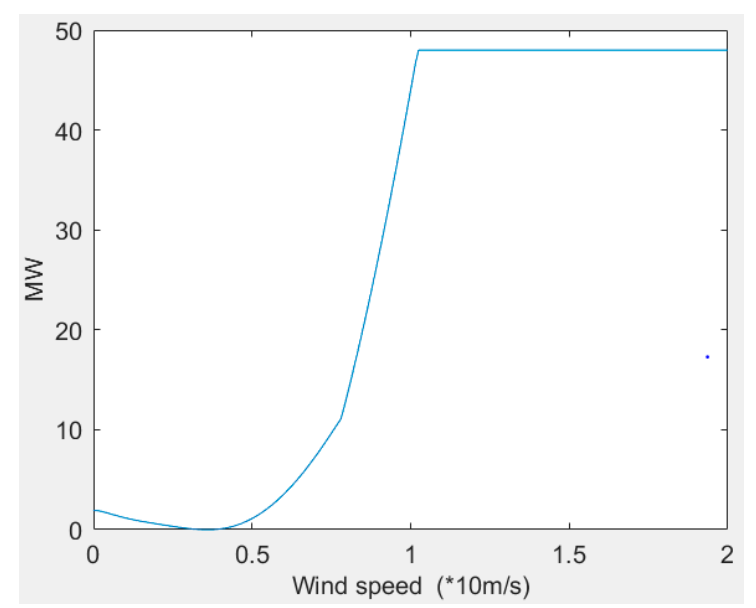

(a) $\tau=1$

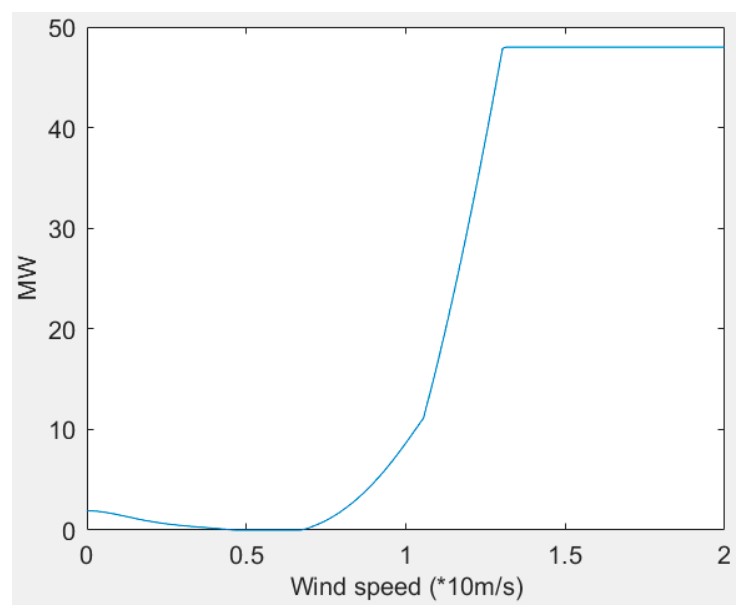

(b) $\tau=4$

Figure 3. The relationship between wind speed and power output.

\subsection{The Effect of Wind Power on the Grid System}

Wind speeds are not constant. The relationship between wind speed and power output shows that, when the former changes, the latter will also fluctuate. In terms of a large time period calculated in hours, the five wind farms face the same wind and their power outputs will fluctuate at the same pace; however, in terms of small time period calculated in seconds, the generators on the same wind farm may have different instantaneous output. To study the effect of intermittent wind power generation on the grid system, this paper still takes the Zhao'an wind farms as an example, to study the effect of power fluctuation on the whole grid system.

Suppose that all the generators face the same wind; the wind speed follows the Weibull distribution, with constant parameters of $\mathrm{C}=20, \mathrm{~K}=3$; and the sample time for wind speed is $1 \mathrm{~s}$; and the filter time constant is $4 \mathrm{~s}$. At the beginning of time 0 , suppose that the wind power output is $50 \%$ and the according wind speed is $7 \mathrm{~m} / \mathrm{s}$. Since the wind speed is unstable, in the following $20 \mathrm{~s}$, the wind speed follows the Weibull distribution. The actual wind speed, filtered wind speed and wind power output evolutions are displayed in Figure 4. The dash-dotted line is the actual wind speed, the solid line is the filtered wind speed and the dashed line is the wind power output. It is clear in Figure 4 that, the rise of wind speed results in a faster rise in wind power output, reaching the full capacity output quickly.

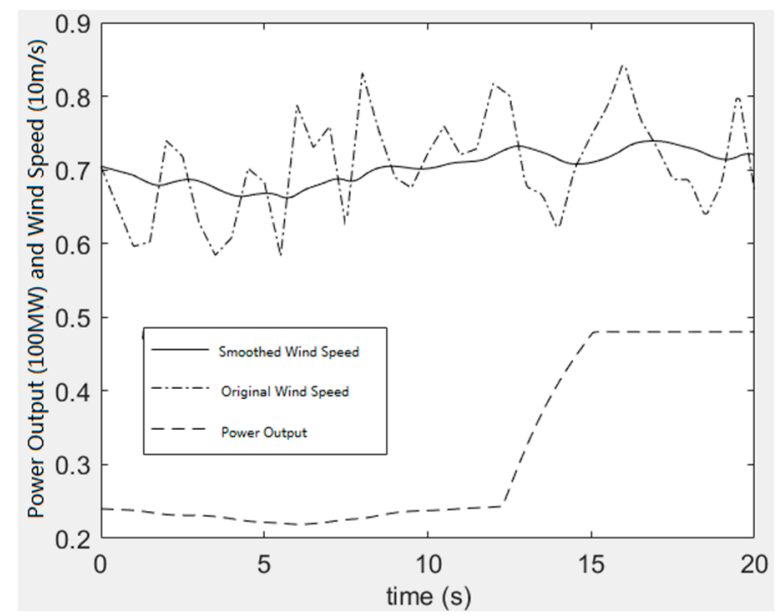

Figure 4. Wind speed and wind power output under the Weibull distribution. 
From the provincial total capacity aspect, $48 \mathrm{MW}$ wind power does not make up a large part of the total installed capacity in Figure A2 in the appendix; yet, the change in wind power output still has a systematic effect on the whole grid system: in addition to the change in the output of the reserve capacity of other generators, there is also a systematic demand for frequency modulation and voltage regulation. Figure 5 illustrates the changes in phase angle and voltage caused by wind power output change. Bus15 refers to the farthest Ningde $500 \mathrm{kV}$ transformer substation, Bus23 refers to the Zhangzhou $500 \mathrm{kV}$ transformer substation and Bus61 refers to the Zhao'an wind farm bus. From Figure 5, it can be seen that, when wind power changes, the effect on bus phase angle is full scale but the change at Bus 23 is much bigger than is that at Bus15 and smaller than is that at Bus61; the effect on voltage is similar, with the farthest bus exhibiting the smallest change.

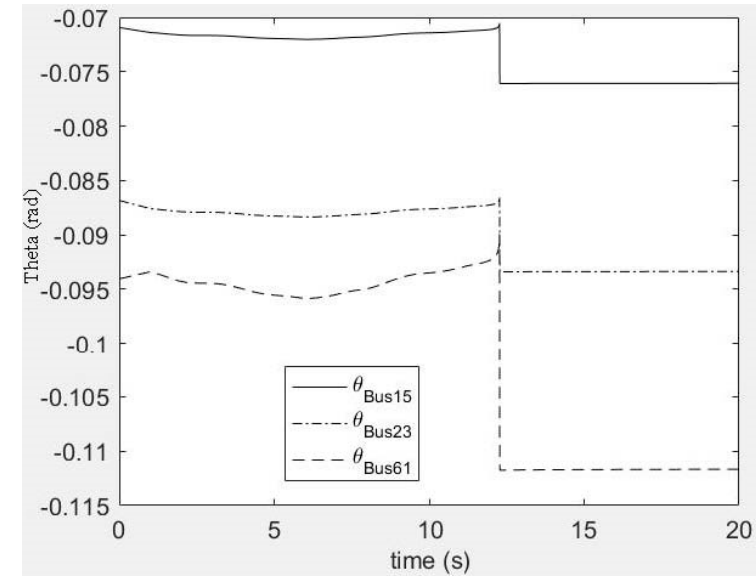

(a)

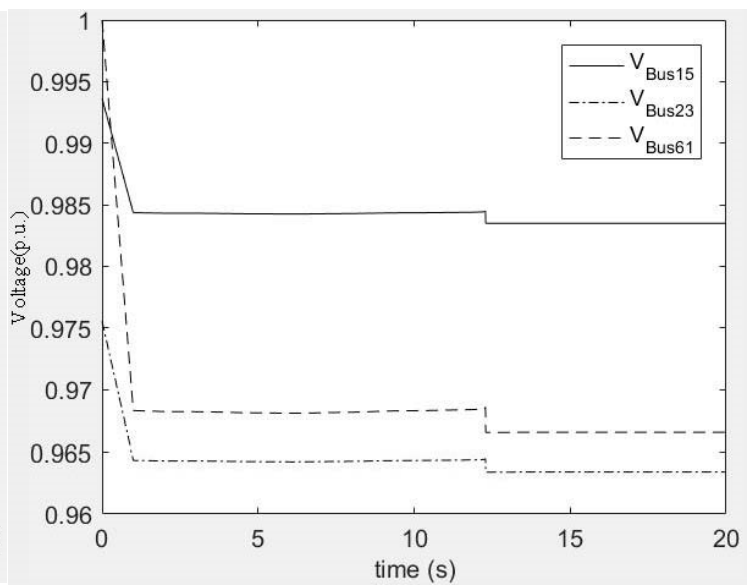

(b)

Figure 5. Effect of wind power output change on systematic phase and voltage. (a) The phase changes; (b) The voltage changes.

\subsection{The Effect of Wind Power Output Change on Electricity Supply Cost}

Short-term and small-scale wind power change affects the grid system balance operation, it can be handled by the system's auto-control units; yet large-scale wind power output fluctuation will affect electricity market trading behavior, resulting in electricity supply cost change and peak following adjustment. To study the effects of wind power output change on the provincial electricity system, this paper takes all the wind power farms into the simulation system illustrated by Figure A2 in the appendix, with a total installed capacity of $1740 \mathrm{MW}$ by the end of 2015. The other wind farms summed at the prefectural level include Quanzhou (44 MW), Putian (592 MW), Fuzhou (528 MW) and Ningde (42 MW). For simplicity, it is supposed that all the demand loads are at $50 \%$ of their highest load level and all the power plants' costs follow the quadratic function described by Equation (3). Under the prerequisite that the grid system keeps in balance, with two scenarios of no wind power output and of wind power outputs at full capacity, the spatial distribution of the electricity supply costs of all the nodes (Buses in the Simulink model) are displayed in Figure 6a,b, respectively. Because of the differences in electricity generation costs across the spatially distributed power plants, in addition to the differences in distances to demand nodes, the line losses result in electricity supply cost differences, as Figure 6a reveals. Since most of the high-efficiency coal-fired power plants and nuclear plants are in Fuzhou City and Ningde City, which are in the north-east part of Fujian, the electricity supply costs there are lower. At the $500 \mathrm{kV}$ grid level, the electricity supply costs of Xiamen City are approximately RMB 10/MWh higher than are those of Ningde City and the cost of the $220 \mathrm{kV}$ level is approximately RMB 8/MWh higher than is that of the $500 \mathrm{kV}$ level because of loss at the transformer substation. However, the cost of the $220 \mathrm{kV}$ level of Zhangzhou city is lower than is that of Xiamen. When wind power supplies the grid system with electricity, the effects are comprehensive. Compared with 
Figure $6 a$, the costs of all the nodes declined, with the degree of decline ranging from RMB 12.85/MWh to RMB 21.52/MWh; the biggest decline is at the Putian node with the biggest wind power capacity.

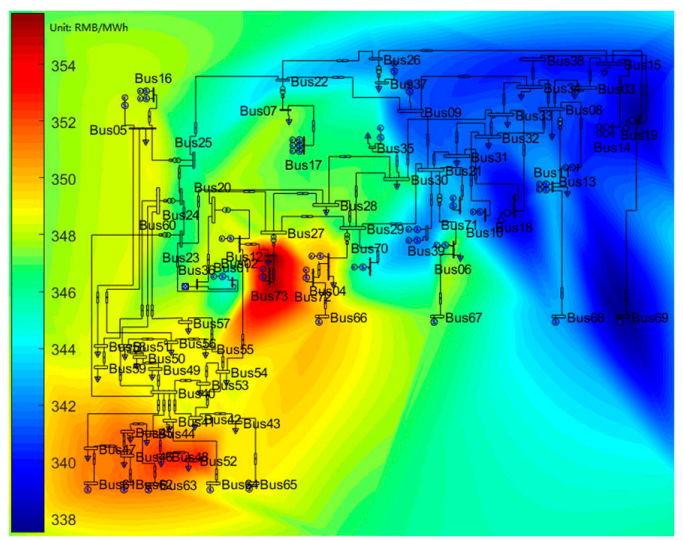

(a)

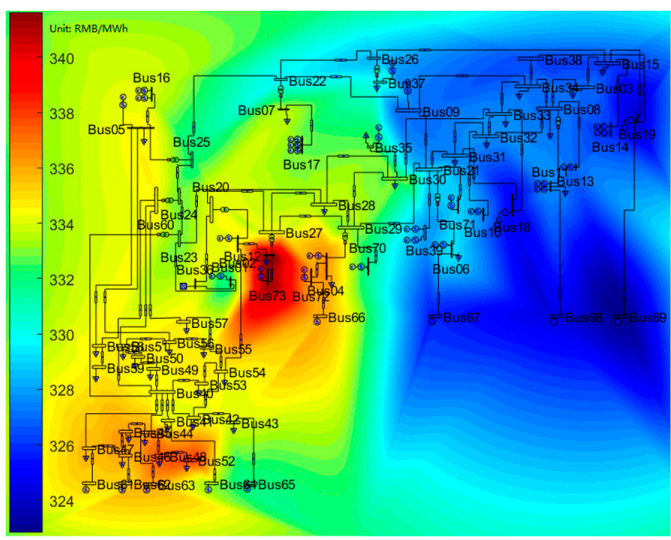

(b)

Figure 6. Comparison of electricity supply costs under different wind power outputs. (a) Supply cost with zero wind output; (b) Supply cost with full wind output.

\subsection{Coordination of Wind Power and PSHP under Competitive Bidding Market}

In non-competitive electricity market, when all the generators have the same cost, OPF minimize the line loss; when the generation costs are different, OPF minimize the electricity supply cost; in competitive market, the OPF maximize the social welfare (consumer surplus + producer surplus) according to the bids in market. Since the spot electricity market of Fujian province has not been founded, the bidding mode in the competitive spot market cannot be confirmed yet. This paper uses the Pool model of the Australian Electricity Market Operator (AEMO) for reference to study the spot market operation. In the AEMO market, the power plants can bid 10 price bands and corresponding powers according to the generators' situation and production costs and these bids can be adjusted according to a changed situation, power plants must balance between getting higher bidding price and the possibility of less generating hours. AEMO sorts these bids by price and obtains the market supply curves. Figure 7 displays parts of the electricity energy supply curves for the 48 trading periods at 1 July 2017 in AEMO; it is clear that the supply curves shift for different trading periods.

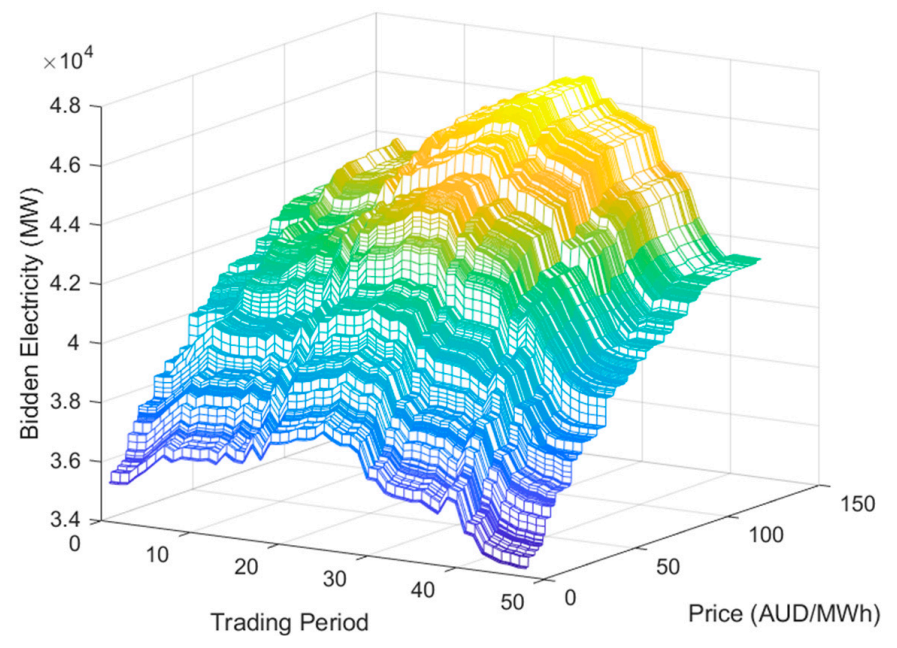

Figure 7. Part of the 48 supply curves in AEMO. 
According to the bidding mode in AEMO, suppose that the coal fired power plants can give 6 price bands according to their condition: to avoid valley peak following and stop/restart costs and to have minimum generating hours, power plants bid prices at half of their average variable cost for powers of $40 \%$ of their capacities; for powers between $40-60 \%$ of their capacities, they bid prices equal to their average variable costs, which range between RMB/MWh 314-370; and for higher powers, taking $10 \%$ of capacity as a band, each band's price equals 1.5 times of that of the former band. Thus, when the generating power is above $90 \%$ of its capacity, the price is approximately 5 times its average cost. Thus, the highest price is rather lower than is that in developed electricity market, for example AEMO. Renewables and nuclear power plants offer only one price to the market and this supposition is due to the unclear attitude of government. The supply curve of Fujian market without wind power is displayed in Figure 8; it's supposed that the power plants do not rebid according to changes in the market situation, which means that the supply curve stays put.

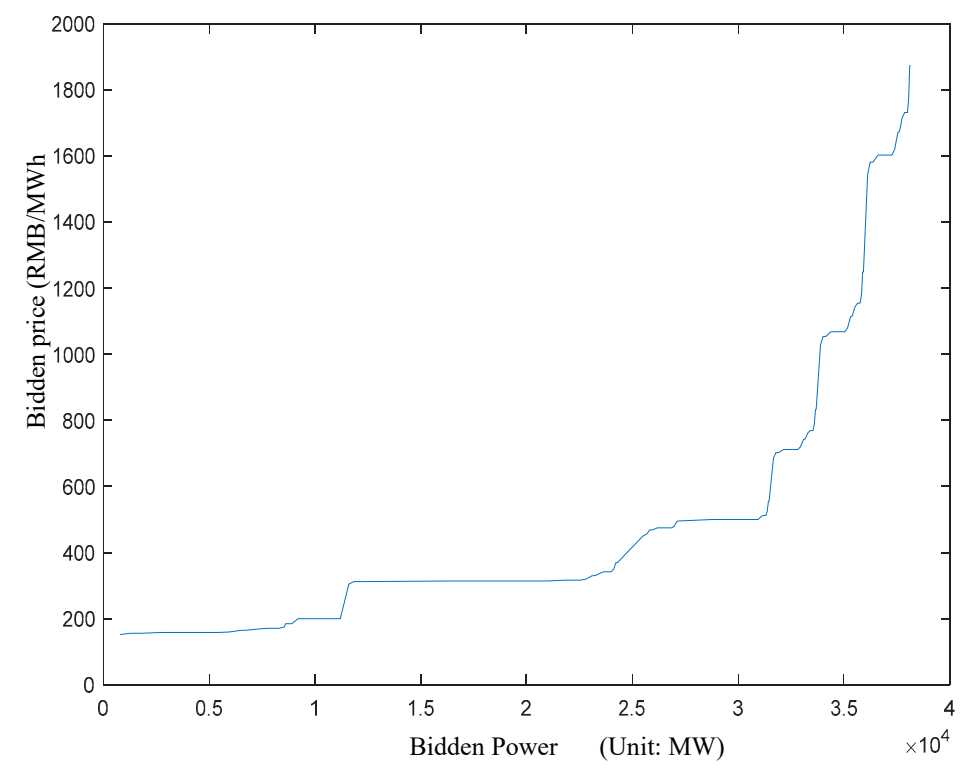

Figure 8. The supply curve of Fujian market.

Wind power is intermittent. Although the wind power along the Fujian coastline is, in general, smallest in early morning and gradually increases to reach its maximum during afternoon to evening, which coincides with the demand load fluctuation, there is no guarantee that they will maintain the same pace. When demand load is low and coal fired power plants are near their minimum power output, large-scale wind power output cannot be absorbed by the electricity system and wind power will be discarded inevitably. Once this happens, using large-scale energy storage, for example, PSHP, to absorb the surplus power will be the only applicable course of action. If suppose the PSHP's pumping threshold price to be RMB 320/MWh, PSHP will begin to pump water when the electricity supply price is lower than that, which raises the electricity demand and supports the market price.

Further, supposing the demand loads are at $50 \%$ of their highest load levels, in the two scenarios of 0 and full wind power output, the distributions of electricity prices are displayed in Figure $9 a, b$, respectively. Compared with Figure 6, it is clear that, under the same demand level, bidding competition squeezes the prices to a lower level and the rise in wind power output will depress the electricity price. From the whole provincial level, the minimum nuclear power is supposed to be $60 \%$ of its capacity, because the Fujian provincial government deliberately let the coal fired power plants bear valley peak following responsibility. When the PSHP's pumping cut in price is fixed at RMB 320/MWh, this has the effect of supporting the whole market; however, the supporting effect is constrained by the pumping load. In Figure 9a, the 8 nuclear generators take 5184 MW generating load, resulting in the coal-fired power plants' generating loads being squeezed to a lower bidding price 
zone and the market price being low enough to start pumping: the electricity price at the pumping node (Bus 35) is only RMB 316.38/MWh and the pumping is operated at the full capacity of $1500 \mathrm{MW}$. Since the PSHP's pumping load has been fully occupied, it has lost further supporting effect to market price. In Figure $9 b$, when all the wind power generators of capacity 1740 MW are generating at full capacity, all the coal-fired plants are squeezed to their limits of valley load following and the decrease in prices of all the nodes range from RMB 110.31-116.76/MWh.

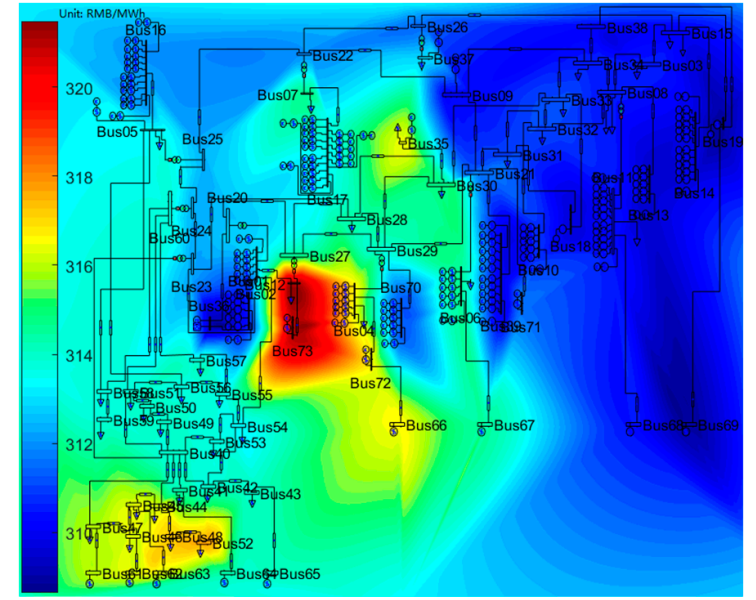

(a)

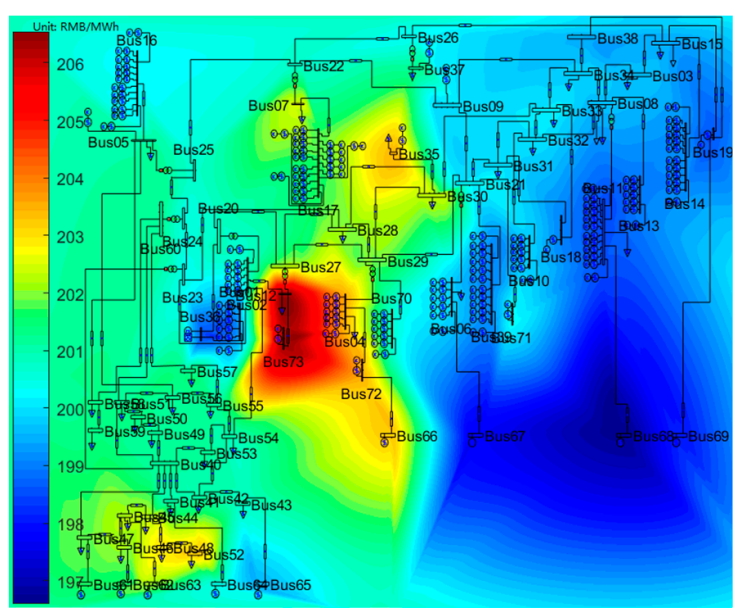

(b)

Figure 9. Comparison of electricity prices in a competitive market. (a) LMPs with zero wind output;

(b) LMPs with full wind output.

It is clear that, if the demand loads reach their 50\% valley levels, the current PSHP with a capacity of $1200 \mathrm{MW}$ cannot meet the requirement of stabilizing the electricity market. Table 2 shows the PSHP's pumping load requirements and generating powers under different demand load levels in two scenarios. In scenario 1, where there is no wind power output, the pumping load should be $1910 \mathrm{MW}$ when the demand load is at $50 \%$; in scenario 2, where the wind power is generating at full capacity, the pumping load should be $3382 \mathrm{MW}$. As the demand load level rise, the pumping load requirement lowers until there is no need to pump to stabilize the market but before that, it can stabilize the local marginal price (LMP) at RMB 320/MWh. When the demand loads rise up to higher levels, for example $80-85 \%$ levels, the generating unit begins to generate and provides power to the system and at the same time stabilize the LMP at RMB 450/MWh before its generating capacity is fully used.

Table 2. PSHP's pumping and generating loads under different scenarios.

\begin{tabular}{|c|c|c|c|c|c|c|c|c|c|c|}
\hline & Demand Load (\%) & 50 & 55 & 60 & 65 & 70 & 75 & 80 & 85 & 90 \\
\hline \multirow{3}{*}{ Pwind $=0 \%$} & Pumping Load(MW) & 1909 & 857 & 218 & 0 & 0 & 0 & 0 & 0 & 0 \\
\hline & Generating Load(MW) & 0 & 0 & 0 & 0 & 0 & 0 & 727 & 1200 & 1200 \\
\hline & LMP of PSHP (RMB/MWh) & 320 & 320 & 320 & 320 & 322 & 342 & 450 & 479 & 492 \\
\hline \multirow{3}{*}{ Pwind $=100 \%$} & Pumping Load(MW) & 3382 & 1903 & 987 & 131 & 0 & 0 & 0 & 0 & 0 \\
\hline & Generating Load(MW) & 0 & 0 & 0 & 0 & 0 & 0 & 0 & 601 & 1200 \\
\hline & LMP of PSHP (RMB/MWh) & 320 & 320 & 320 & 320 & 321 & 322 & 340 & 450 & 478 \\
\hline
\end{tabular}

However, under the current economic downturn and electricity oversupply condition, the installed capacity of Fujian province is growing at a higher rate than is demand, let al.one the fact that most of them are valley-load-following free nuclear and wind powers, which will present a serious challenge to the development of the Fujian electricity market. 


\section{An Example of PSHP Operation}

The analysis above in 3.4 reveals only a snapshot of the electricity market operation; it cannot reveal the system operation dynamically. In any normal working day, the electricity demand load will fluctuate over time. In Figure 10, the dotted black line displays the 15-min real demand load change at the provincial system control level for a certain day in May 2016. In the system described in Figure A2 in the appendix, the total installed capacity of coal, hydro, nuclear and gas is $36,950 \mathrm{MW}$; the total demand load, not including the pumping load at PSHP, is 32,885 MW; there is also wind power with capacity of 1740 MW; the Xiyuan PSHP's generator capacity is 1200 MW. In 2016, the highest demand load was $32,360 \mathrm{MW}$, which is very close to the total demand load in the simulation model.

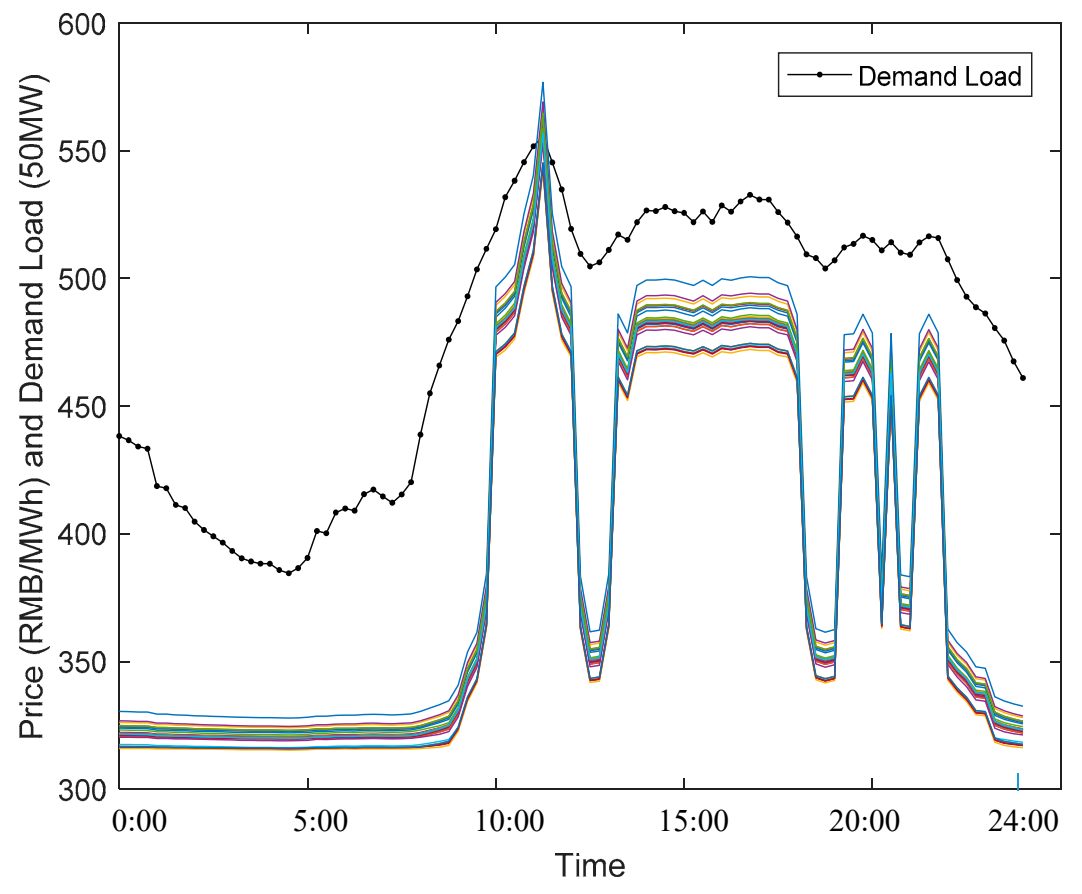

Figure 10. The load and price changes.

Under the competitive bidding market, first suppose that the demand is met by traditional coal, hydro and nuclear powers, the price fluctuations of all the demand nodes are also displayed in Figure 10. The price fluctuation has three characteristics: firstly, the prices are rather stable at the valley load period, this is because the total demand loads fall into the low price bids zone, prices will be supported by PSHP's pumping loads, which provides supporting effect to the whole system and that's why all the prices stay around 320 for the whole period of 0:00-8:00; secondly, the difference amongst all the nodes changes along with loads levels; thirdly, at high loads, small changes in demand may result in a big jump in electricity price, for example, at 12:00 the demand loads decline a little, after which the price declines by more than RMB 100, later rising up quickly and the fluctuation becomes more violent between 18:00 and 22:00. Small changes in demand resulting in big jumps in price are not rare in the developed electricity market.

In the simulation model, the pumping threshold price is supposed at RMB 320/MWh and the out/ in efficiency is fixed at $80 \%$, which means that the minimum supplying price of PSHP should be RMB 400/MWh; to make a certain level of profit, suppose the bidding price of PSHP to be RMB 450/MWh and accept a higher market price when demand loads rise; and suppose that the three gas peaking plants' bidding prices are all RMB 500/MWh. For the demand load changes in Figure 10, the electricity prices of all the demand nodes are displayed in Figure 11. Compared with Figure 10, it is clear that PSHP and gas peaking plants can stabilize the market price at two levels of RMB 450 and 500/MWh. Except for the highest peak load, at around 11:00, the peak loads at other times are 
effectively limited by PSHP's generating power; only when the PSHP is generating at full capacity and peak load following is constrained will the electricity price rise again, although limited by the gas peaking plants' bidding price. If the demand load rises farther and the gas peaking generator operates at full capacity, the electricity price will rise more.

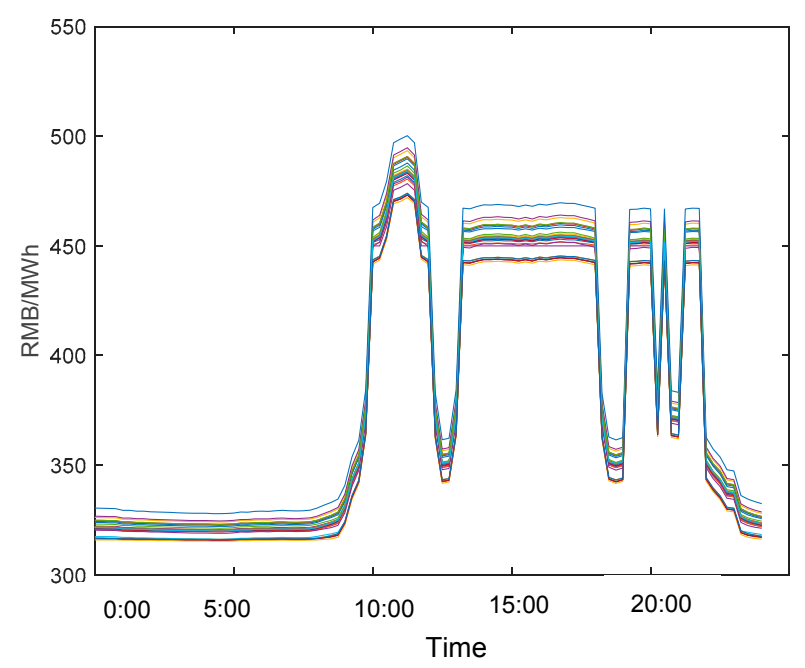

Figure 11. Price changes under peaking following powers.

For the given load curve in Figure 10, PSHP and gas power will lower the social cost by RMB 6.31 million; however, the PSHP's gross profit when accepting a higher market price is only RMB 0.32 million and the gross profit when accepting fixed prices is only RMB 0.28 million, which can hardly compensate for the fixed cost of PSHP.

\section{Conclusions and Policy Implications}

This paper takes the Fujian provincial grid system as the framework to construct an independent electricity system model according to the connection situation of power plants, the production costs of coal-fired power plants and demand load data. Under this system, this paper studies the meanings and scale requirement of PSHP when the capacities of intermittent wind power and stable nuclear power keep growing. Firstly, this paper simulates the relationship between wind speed and wind power output, with the results being very close to the actual parameters of wind power generators; secondly, analyzes the effects of wind power fluctuation on grid system stabilization; thirdly, calculates the effects of wind power output fluctuation on electricity supply cost when coal power production cost follows a quadratic function; and fourthly, calculates the effects of wind power fluctuation on electricity prices under a competitive bidding spot market and the stabilizing effects and the scale requirement of PSHP to stabilize the market. Finally, using the daily load curve, analyzes the electricity market operation and price fluctuation and the price stabilizing effects of PSHP and gas peak following generators. The results show that, although PSHP has a large external social welfare effect, it can hardly earn enough profit.

There are three shortcomings in this study: (1) as the electricity market is not fully marketized and the current electricity market is oversupplied, the study can only be based on simulation, rather than real market behavior; (2) the trading rules of the future electricity market are not finalized and the trading mode can only be subjectively supposed based on developed market experience; (3) the simulation results are limited, because the system keeps the intermittent renewable powers and gas peaking powers out, and, through not considering the potential earnings from the ancillary market, the profit potential of PSHP is underestimated. However, the results of this paper still have directional 
meanings for reference. Based on the conclusions of this study, some suggestions are put forward for the marketization to come.

(1) When installing more wind and nuclear power plants, more PSHP plants are needed. Although developing wind and nuclear power is the inevitable choice to combat global warming, wind power and nuclear power are at two extremes from the perspective of stability and they pose great challenges to the grid system. Energy storage facilities, represented by PSHP, can offer an effective buffer between electricity supply and demand.

(2) Electricity market reform should continue and the spot market design should give participants enough flexibility. A spot market is usually a short-term adjustment market compensating for the shortcomings of the bilateral market, forming supply and demand curves to reveal the market situation in the short-term, providing power plants and consumers with information and economic incentives to adjust their behaviors. A multi-price bands' bidding mode can offer participants flexible choices to maximize their welfare.

(3) Hydro power generation has speed and cost advantages in terms of stopping, restarting and load following and it can play greater roles in ancillary service markets. When designing the ancillary service trading mode, these advantages should be taken into consideration, making more space for PSHP earning profit and helping the electricity market function fluently.

(4) More studies about energy storage and PSHP choice should be carried out. This paper proves that PSHP has a substantial social external welfare effect but struggles to make enough profit. As the planned $13 \mathrm{GW}$ of offshore wind power plants are put into operation in the future, they will have a greater effect on the electricity market; thus, system operation, coordination of renewable power and energy storage, including PSHP, requires further study.

Acknowledgments: This paper is supported by National Natural Science Foundation of China (NSFC) project (No. 71573217) and the Ministry of Education in China (MOE) Project of Humanities and Social Sciences (No. 13YJC790110). The author would like to thank the anonymous referees for helpful comments and suggestions and the author is responsible for the paper. Data are available to readers on request.

Conflicts of Interest: The authors declare no conflict of interest.

\section{Nomenclature}

$\begin{array}{ll}\text { AC } & \text { Alternating Current } \\ \text { AEMO } & \text { Australian Electricity Market Operator } \\ \text { AVC } & \text { Average Variable Cost } \\ \text { CIF } & \text { Cost Insurance and Freight } \\ \text { GW } & \text { Gigawatt } \\ \text { MW } & \text { Megawatt } \\ \text { NDRC } & \text { National Development and Reform Commission () } \\ \text { OPF } & \text { Optimal Power Flow } \\ \text { PSHP } & \text { Pumping and Storage Hydro Power } \\ \text { RMB } & \text { Renminbi Yuan, the exchange rate of RMB/USD at 2018.1.1 is } 6.50\end{array}$




\section{Appendix A}

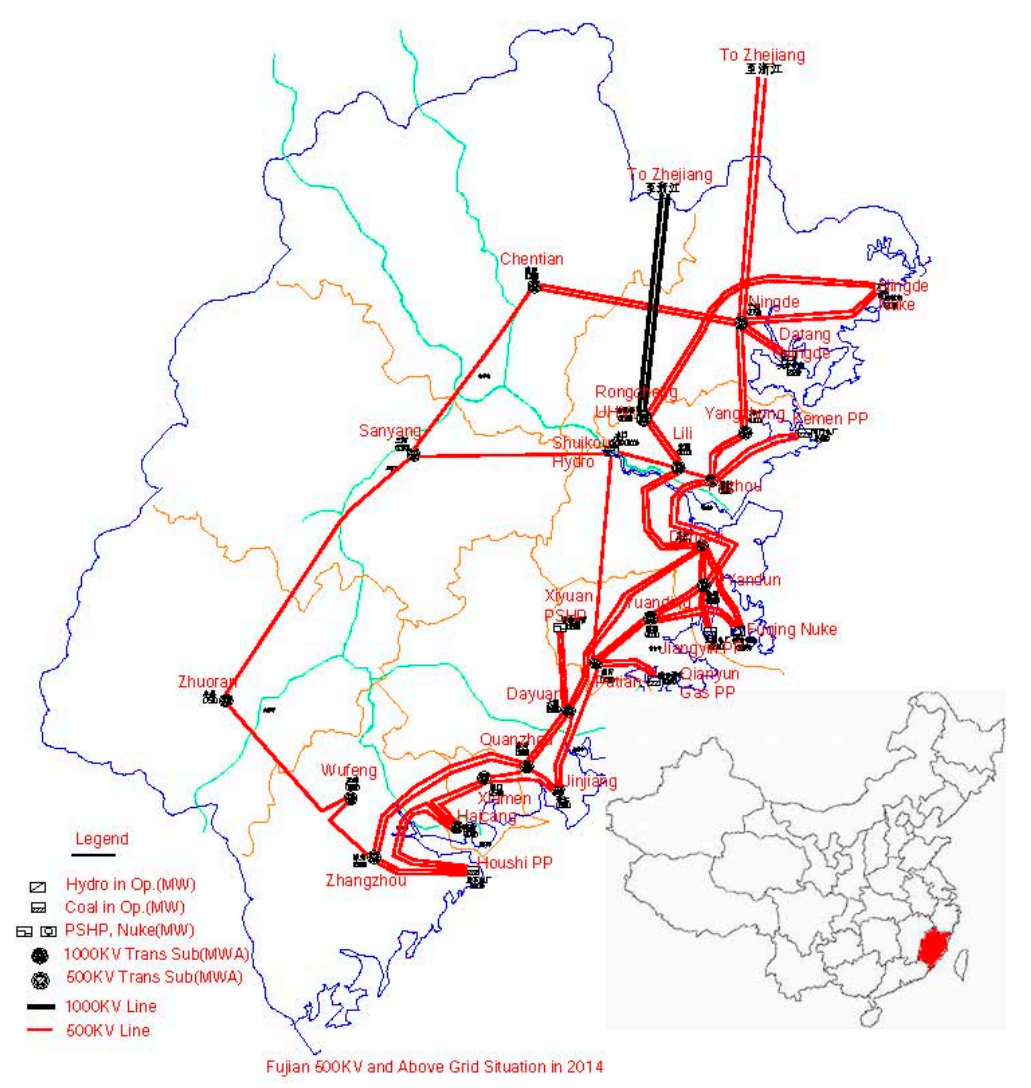

Figure A1. Fujian $500 \mathrm{kV}$ and above grid, power plant distribution map.

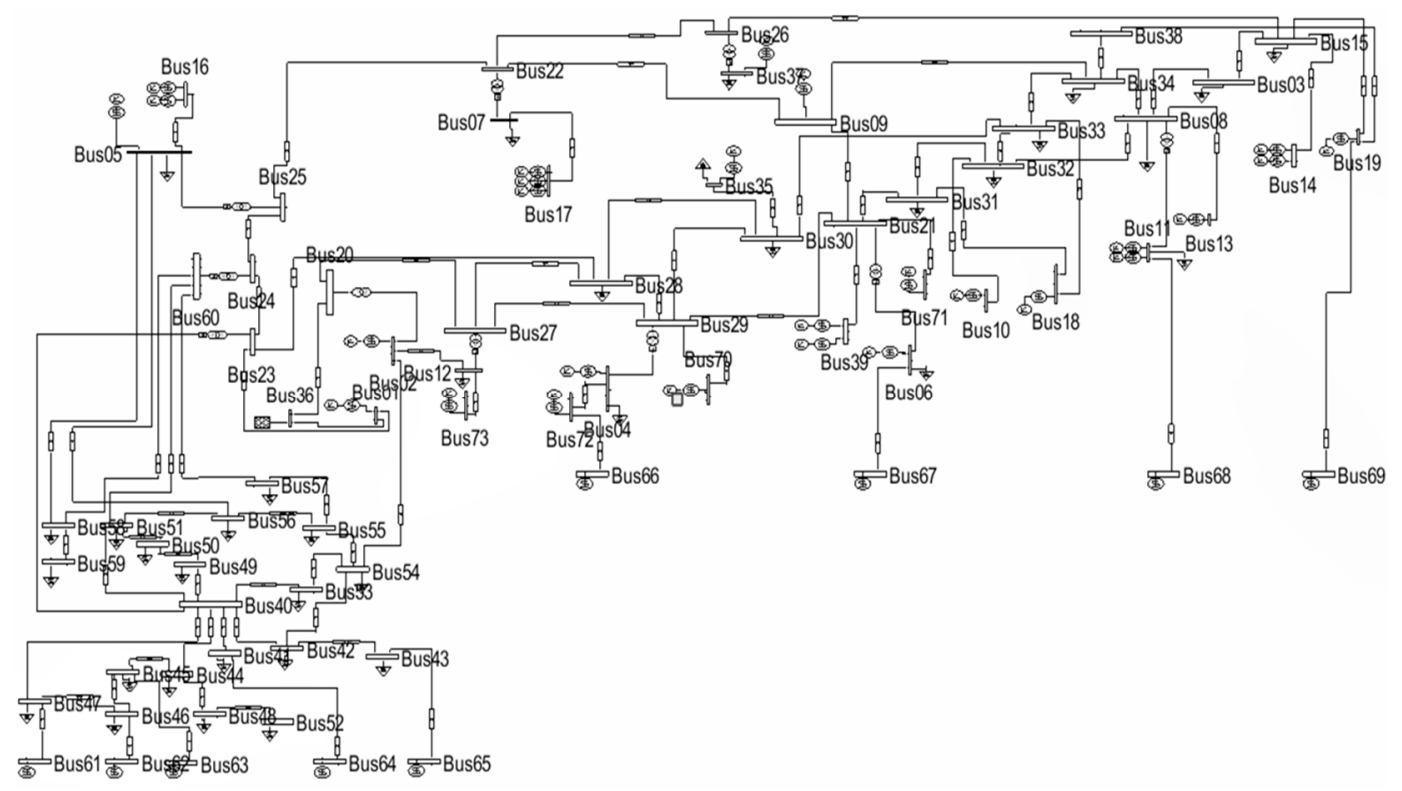

Figure A2. The Simulink model of Fujian electricity market for wind power.

\section{References}

1. Document: The State Council Issued the Notice on Issuing Electric Power Sector Reform. Available online: http: / / en.pkulaw.cn/ display.aspx?cgid=178553\&lib=law (accessed on 19 January 2018). 
2. Suggestions on Further Deepening the Reform of Electric Power System. Available online: http://www. scirp.org/\%28S\%281z5mqp453edsnp55rrgjct55\%29\%29/reference/ReferencesPapers.aspx?ReferenceID= 2011305 (accessed on 19 January 2018).

3. Denny, E.; Tuohy, A.; Meibom, P.; Keane, A.; Flynn, D.; Mullane, A.; O’Malley, M. The impact of increased interconnection on electricity systems with large penetrations of wind generation: A case study of Ireland and Great Britain. Energy Policy 2010, 38, 6946-6954. [CrossRef]

4. Mc Garrigle, E.V.; Leahy, P.G. Cost savings from relaxation of operational constraints on a power system with high wind penetration. IEEE Trans. Sustain. Energy 2015, 6, 1-8. [CrossRef]

5. Shaker, H.; Zareipour, H.; Wood, D. Impacts of large-scale wind and solar power integration on California's net electrical load. Renew. Sustain. Energy Rev. 2016, 58, 761-774. [CrossRef]

6. Huber, M.; Dimkova, D.; Hamacher, T. Integration of wind and solar power in Europe: Assessment of flexibility requirements. Energy 2014, 69, 236-246. [CrossRef]

7. Zakeri, B.; Rinne, S.; Syri, S. Wind Integration into Energy Systems with a High Share of Nuclear Power-What Are the Compromises? Energies 2015, 8, 2493-2527. [CrossRef]

8. Pudjianto, D.; Aunedi, M.; Djapic, P.; Strbac, G. Whole-Systems Assessment of the Value of Energy Storage in Low-Carbon Electricity Systems. IEEE Trans. Smart Grid 2014, 5, 1098-1109. [CrossRef]

9. Kondoh, J.; Ishii, I.; Yamaguchi, H.; Murata, A.; Otani, K.; Sakuta, K. Electrical energy storage systems for energy networks. Energy Convers. Manag. 2000, 41, 1863-1874. [CrossRef]

10. Ibrahim, A.; Ilinca, J.; Perron, J. Energy storage systems-Characteristics and comparisons. Renew. Sustain. Energy Rev. 2008, 12, 1221-1250. [CrossRef]

11. Nyamdash, B.; Denny, E.; O'Malley, M. The viability of balancing wind generation with large scale energy storage. Energy Policy 2010, 38, 7200-7208. [CrossRef]

12. Suul, J.A.; Uhlen, K.; Undeland, T. Variable Speed Pumped Storage Hydropower for Integration of Wind Energy in Isolated Grids: Case description and control strategies. In Proceedings of the Nordic Workshop on Power and Industrial Electronics (NORPIE/2008), Espoo, Finland, 9-11 June 2008.

13. Deane, J.P.; Ò'Gallachóir, B.P.; McKeogh, E.J. Techno-economic review of existing and new pumped hydro energy storage plant. Renew. Sustain. Energy Rev. 2010, 14, 1293-1302. [CrossRef]

14. Mc Daniel, G.H.; Gabrielle, A.F. Dispatching pumped-storage generation. IEEE Trans. Power Appara. Syst. 1966, PAS-85, 465-471. [CrossRef]

15. Cohen, A.I.; Wan, S.H. An algorithm for scheduling a large pumped-storage plant. IEEE Trans. Power Appar. Syst. 1985, PER-5, 40.

16. Oliviera, P.; McKee, S.; Coles, C. Optimal scheduling of a hydro thermal power generation system. Eur. J. Oper. Res. 1993, 71, 334-340. [CrossRef]

17. Yang, C.; Jackson, R.B. Opportunities and barriers to pumped hydro energy storage in the United States. Renew. Sustain. Energy Rev. 2011, 15, 839-844. [CrossRef]

18. Horsley, A.; Wrobel, A.J. Effciency rents of pumped-storage plants and their uses for operation and investment decisions. J. Econ. Dyn. Control 2002, 27, 109-142. [CrossRef]

19. Lu, N.; Chow, J.H.; Desrochers, A.A. Pumped-storage hydro-turbine bidding strategies in a competitive electricity market. IEEE Trans. Power Syst. 2004, 19, 834-841. [CrossRef]

20. Kanakasabapathy, P.; Swarup, S. Bidding Strategy for Pumped-Storage Plant in Pool-Based Electricity Market. Energy Convers. Manag. 2010, 51, 572-579. [CrossRef]

21. Dogan, K. Uncertainties in Energy Markets and Their Consideration in Energy Storage Evaluation; KIT Scientific Publishing: Karlsruhe, Germany, 2013; Volume 4.

22. Abgottspon, H.; Bucher, M.; Andersson, G. Stochastic dynamic programming for unified short and medium-term planning of hydro power considering market products. In Proceedings of the 12th IEEE International Conference on Probabilistic Methods Applied to Power Systems (PMAPS), Istanbul, Turkey, 10-14 June 2012.

23. Braun, S. Hydropower Storage Optimization Considering Spot and Intraday Auction Market. Energy Procedia 2016, 87, 36-44. [CrossRef]

24. Kumar, N.; Besuner, P.M.; Lefton, S.A.; Agan, D.D.; Hilleman, D.D. Power Plant Cycling Costs. 2012. Available online: https:/ / www.nrel.gov/docs/fy12osti/55433.pdf (accessed on 21 January 2018).

25. Deb, R. Operating hydroelectric plants and pumped storage units in a competitive environment. Electr. J. 2000, 13, 24-32. [CrossRef] 
26. Ela, E.; Kirby, B.; Botterud, A.; Milostan, C.; Krad, I.; Koritarov, V. The Role of Pumped Storage Hydro Resources in Electricity Markets and System Operation. In Proceedings of the HydroVision International Conference, Denver, CO, USA, 23-26 July 2013.

27. Kirby, B. Co-Optimizing Energy and Ancillary Services from Energy Limited Hydro and Pumped Storage Plants. In Proceedings of the 2012 HydroVision International, Tulsa, OK, USA, 17-20 July 2012.

28. Saarinen, L.; Dahlbäck, N.; Lundin, U. Power system flexibility need induced by wind and solar power intermittency on time scales of 1-14 days. Renew. Energy 2015, 83, 339-344. [CrossRef]

29. Mou, D. Understanding China's electricity market reform from the perspective of the coal-fired power disparity. Energy Policy 2014, 74, 224-234. [CrossRef]

30. Ogayar, B.; Vidal, P.G.; Hernandez, J.C. Analysis of the cost for the refurbishment of small hydropower plants. Renew. Energy 2009, 34, 2501-2509. [CrossRef]

31. NDRC's Notice on the Adjustment of PV Power and Onshore Wind Power Benchmarking Feed-in Prices (Fagaijiage [2016], No.2729). Available online: http:/ / www.ndrc.gov.cn/gzdt/201612/t20161228_833065. html (accessed on 19 January 2018).

(C) 2018 by the author. Licensee MDPI, Basel, Switzerland. This article is an open access article distributed under the terms and conditions of the Creative Commons Attribution (CC BY) license (http:/ / creativecommons.org/licenses/by/4.0/). 